\title{
An Integrated Factor Analysis Model for Product Eco-Design Based on Full Life Cycle Assessment
}

\author{
Zhifang Zhou ${ }^{1,2}$, Tian $\mathrm{Xiao}^{1}$, Dayuan $\mathrm{Li}^{1,2^{*}}$ \\ ${ }^{1}$ Business School, Central South University, Changsha, Hunan-410083, '2 Collaborative Innovation Center of Resource- \\ conserving \& Environment- friendly Society and Ecological Civilization, Central South University, Changsha, Hunan- \\ 410083 (China)
} 32f3721@qq.com,tianxia08023@gmail.com,*Corresponding author:bigolee@163.com

Received: June 2015

Accepted: January 2016

\section{Abstract:}

Purpose: Among the methods of comprehensive analysis for a product or an enterprise, there exist defects and deficiencies in traditional standard cost analyses and life cycle assessment methods. For example, some methods only emphasize one dimension (such as economic or environmental factors) while neglecting other relevant dimensions. This paper builds a factor analysis model of resource value flow, based on full life cycle assessment and eco-design theory, in order to expose the relevant internal logic between these two factors.

Design/methodology/approach: The model considers the efficient multiplication of resources, economic efficiency, and environmental efficiency as its core objectives. The model studies the status of resource value flow during the entire life cycle of a product, and gives an in-depth analysis on the mutual logical relationship of product performance, value, resource consumption, and environmental load to reveal the symptoms and potentials in different dimensions.

Findings: This paper illustrates logical relationships among resource efficiency, economic efficiency and environmental efficiency, builds a fully comprehensive evaluation analysis model to trace, evaluate and analyze the status of the material and value flow of the product life cycle process. 
Originality/value: This provides comprehensive, accurate and timely decision-making information for enterprise managers regarding product eco-design, as well as production and management activities. To conclude, it verifies the availability of this evaluation and analysis model using a Chinese SUV manufacturer as an example.

Keywords: eco-design, full life cycle assessment, resource value flow, resource efficiency, economic efficiency, environmental efficiency

\section{Introduction}

Eco-design is an approach to product design that makes special consideration of the environmental impact of the product during its entire life cycle. Eco-design of a product, including any variations in ecological design patterns, has a critical impact on the status of the product's material and value flow during its entire production process. The cost and value of the product and its associated environmental load and consumption of resources are also affected. To this effect, it is necessary to comprehensively evaluate and analyze the status of the material and value flow of a product's life cycle so as to provide complete and timely eco-design information.

There are variable comprehensive evaluation methods on the horizon, However, there are defects and deficiencies in the existing evaluation and analysis methods. For example, some methods only focus on one aspect of the product (economic or environmental factors, ) despite varying degrees of impairment, moreover relatively fewer methods for comprehensive evaluation and analysis of the product system.

The primary objective of this paper is to build a fully comprehensive evaluation analysis model which can trace, evaluate, and analyze the status of the material and value flow of the product life cycle process, from the three harmonization perspectives (resources, environment, and economy). Based on the concept and principle of the IPAT equation, this paper builds the total factor evaluation analysis model and creates specific evaluation by seeking a strict number of logical relationships between resource efficiency, economic efficiency and environmental efficiency. This paper also completes the analysis of the different stages of resource flow in the life cycle of products by constructing an $X, Y, Z$ multiples evaluation factor at the core of the relationship between the product performance, resource consumption and environmental load.

\section{Review on Traditional Evaluation and Analysis Methods of Product}

For the sake of assessment, the life cycle of a product is usually divided into four parts: procurement, manufacture, use, and disposal (Jeganova, 2004; Yamamoto \& Wang, 2003). 
Resource and environmental factors are crucial to the product's design. Environmental performance goals are carefully set for the product, in order to leave minimal environmental impact (COM, 2003; Ortiz, Raluy \& Serra, 2007). The objective is not only to reduce the consumption of materials and energy and the emission of harmful substances, but also to make the products and parts easily retrievable, recyclable and re-usable (Bhander, Hauschild \& McAloone, 2003; Sakao, 2007).

\subsection{Standard Costs and Variance Analysis Mode}

This model introduces a standard cost and target cost ideology, and establishes cost standards as well as proportion standards of cost allocation for different product cost types. The comparative analysis on the variance between actual cost and standard cost and the evaluation of its causes provide basic information that controls decision-making. There are two key points for the implementation of this evaluation analysis model. First, the cost standard is the staff's goal, along with the scale to measure the actual cost savings or cost overages, which create in-process control. Second, by comparing the actual consumption of cost against standard consumption, analyzes on the differences from the cost standards and identifying the attributes of responsibility provides a basis for decision-making and improved measures of control. With the cost variance as the core, the standard cost evaluation model can analyze and evaluate the locations of costs incurred and create clear attributes of responsibility. However, this analysis model is difficult to apply to the entire eco-design process due to the lack of an ecological perspective and extensive cost concept as well as analysis boundary. It is hard for an enterprise that has not applied the environmental cost accounting to set a standard cost, let alone analysis cost variances.

\subsection{Resource Flows Cost Analysis Model}

During the production process, the purpose of resource flows cost analysis is to continually decrease production costs, and to improve economic and ecological benefits using the resource flow cost accounting information. Its evaluation and analysis methods are fragmented, however, have not form into a complete system. The main methods include the internal resources flows cost evaluation and analysis, external environmental damage costs evaluation and analysis, and the matrix evaluation and analysis mode, which combines both methods above (Zhou, 2014; Zhou, Chen \& Xiao, 2013a; Zhou, Chen, Xiao \& Xiong, 2013b). The resource flow cost analysis model can clearly delineate resource consumption and loss of product during the manufacturing process, and damage costs caused by the external environment. It can locate key improvements to the product manufacturing process in effort to reduce resource consumption and enhance environmental and economic benefits. However, 
over the process of a product's life cycle, apart from manufacturing sectors, it must include transportation, consumption, recycling, and other relevant factors. The analytic model cannot be applied mechanically, unless innovative improvements could be adapted according to different enterprises' reality.

\subsection{Factor $X$ Indicator Method}

The concept "eco-efficiency" was suggested by the World Business Council for Sustainable Development (WBCSD), enhanced by R. Yamamoto and became the base of Factor $\mathrm{X}$ indicator method, which aims at evaluating eco-design, manufacture and environmental burden of products as well as assessing technology improvement and eco-efficiency. It can quantify the relationship between product value and environmental influence and release the ideal condition that if a conventional product can be produced at $1 / \mathrm{X}$ times of its environmental impact cost, the eco-efficiency will be considered to improving by X times (Factor X) (Yamamoto, 1999). The connotation of eco-efficiency and Factor $X$ in the method can be defined by the following equations (Takahashi, 2005; Aoe, 2006, 2007).

$$
\text { eco-efficiency }=\frac{\text { value of new product }}{\text { environmental influence of new product }}
$$

$X$ multiple evaluation factors of product $=\frac{\text { eco-efficiency of new product }}{\text { eco-efficiency of old product }}$

The Factor $X$ indicator qualified the advantages such as simplicity and high usability, it can be used to evaluate and analyze (both before and after optimization, the before and after value of product eco-design and any improvement of the product's environmental impact. However, it still does not reflect the mutual logical relationships between product performance, product value and environmental impact of product, which are the three core factors in eco-design considerations. Therefore, we need to improve the $X$ multiple evaluation factors with the absorption value of engineering principles in this paper.

\subsection{Life Cycle Assessment Method}

Among all the evaluating and analyzing methods of the production system, the life cycle evaluation (LCA) is the most common. In general, the basic framework of LCA can be divided into four stages: the determination of purpose and scope, inventory analysis, impact assessment and interpretation of results (Graedel, Allenby \& Comrie, 1995). The most well-known life cycle impact evaluation systems are EPS in Sweden, and Eco-indicator in the Netherlands (Muñoz, Rodríguez, Rosal \& Fernández-Alba, 2009; Renou, Thomas, Aoustin \& 
Pons, 2008; van der Velden, Kuusk \& Köhler, 2015). LCA evaluation mainly functions using a matrix method, analytic hierarchy process, and multi-objective decision-making optimization method. These current models also have their own advantages and disadvantages (Jonsson \& Svensson, 1997; Spengler, Geldermann, Hahre, Sieverdingbeck \& Rentz, 1998). For example, data requirement is low for the matrix method, but is subjective; Analytic Hierarchy Process can solve the problem of weight, but determining the degree of membership is subjective and largely uncertain; Multi-objective decision optimization can provide evaluation results under different assumptions and provide choices to decision-makers, but the expression of specific results have a certain degree of difficulty due to many influencing factors.

Life cycle assessment has been widely used abroad, but there are some drawbacks in the methodology and practical application, such as subjective evaluation, less precise data, uncertain results and more. Therefore, few domestic case studies have been performed. There are many shortcomings in other methods, such as substance metabolism analysis, evaluation of circular economy, and others (Xiong, Xiao, Chen \& Zhou, 2015). Traditional methods do not adequately meet the needs of the resource value flow assessment and analysis in products' life cycles for eco-design. So this paper tries to built an integrated factor analysis model based on Factor $X$ indicator model, resource value flow method and Life cycle assessment for product eco-design.

\section{The Logical Association among Eco-Design, Three Dimension Benefits and Resources Flow Cost}

\subsection{The Mechanism of the Eco-Design with Products Resource, Economic and Environmental Benefits}

Before apply product eco-design, the benefits that heavily rely on terminal controls are mainly reflected as explicit environmental benefits which can be direct measured as the effects of enterprise's pollution control, denoted as $\mathrm{P}_{0}$. After the implementation of eco-design, the connotation of environmental benefits extends, mainly embodies a wide range of indicators available in corporate environmental management systems and eco-design strategy for the enterprise to improve the eco-efficiency of pollution prevention, which is denoted by $\mathrm{P}_{1}$; constraints by material resources, the condition that enterprise is forced to reduce resource consumption is noted as $\mathrm{O}_{0}$, after technological innovation and dynamic adjustment of resource savings arranged by eco-design naturally saving resource as $\mathrm{O}_{1} ; \mathrm{E}_{0}$ stands for the economic effects that only include simple financial indicators that measure corporate value and operating results before ecological design, applied products eco-design $E_{1}$ goes further by adding non-financial indicators, like enterprise reputation and efficiency in the market, to depict the comprehensive economic efficiency. 
Thus enterprises achieve ideal condition of all three dimensions, namely resource efficiency, economic efficiency and environmental benefits. The effects of applying eco-design are shown in Figure 1.

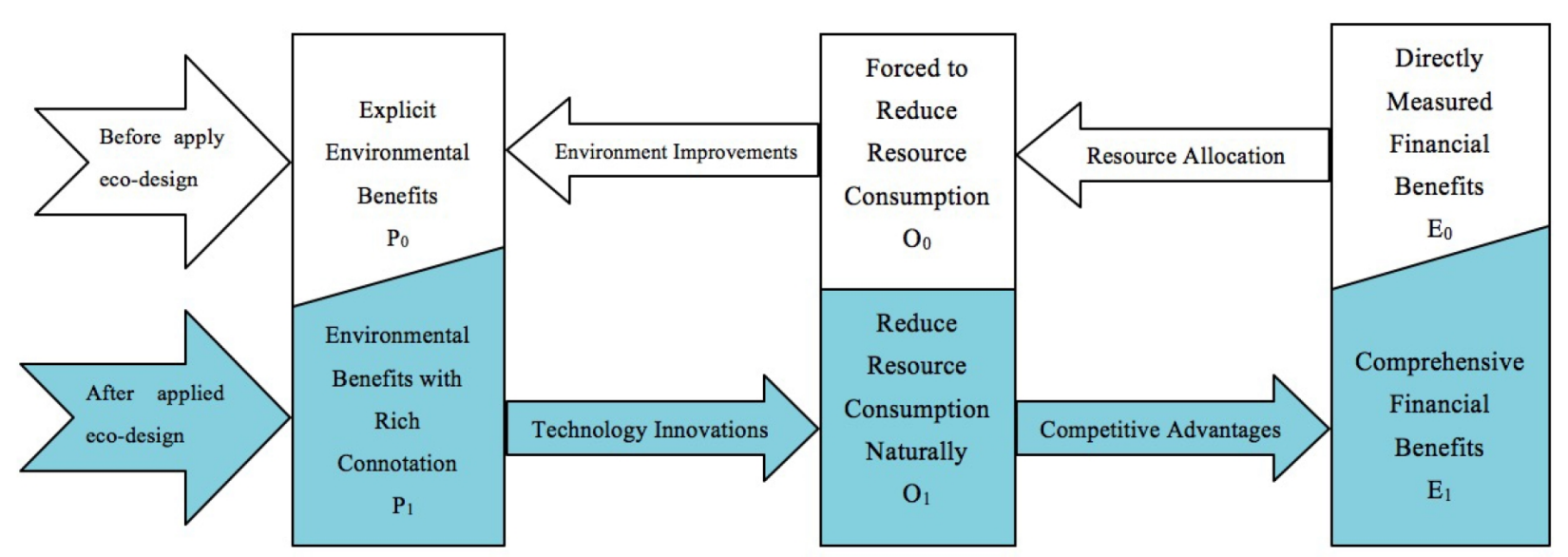

Figure 1. Mechanistic model of eco-design and products resources, economic and environmental benefits

\subsection{The Mechanism between Ecological Design and Resource Value Flow}

In eco-design, consumers and stakeholders increasingly require high standards of environmental performance for products, in addition to their basic functions or quality. Enterprisers must consider the use value of a product (its function,) its market value (cost,) and environmental value (external costs). Therefore, its resources flow extends forward from the design stage, but also back from the product's use, recycling and disposal stages. The resources flow route is shown in Figure 2.

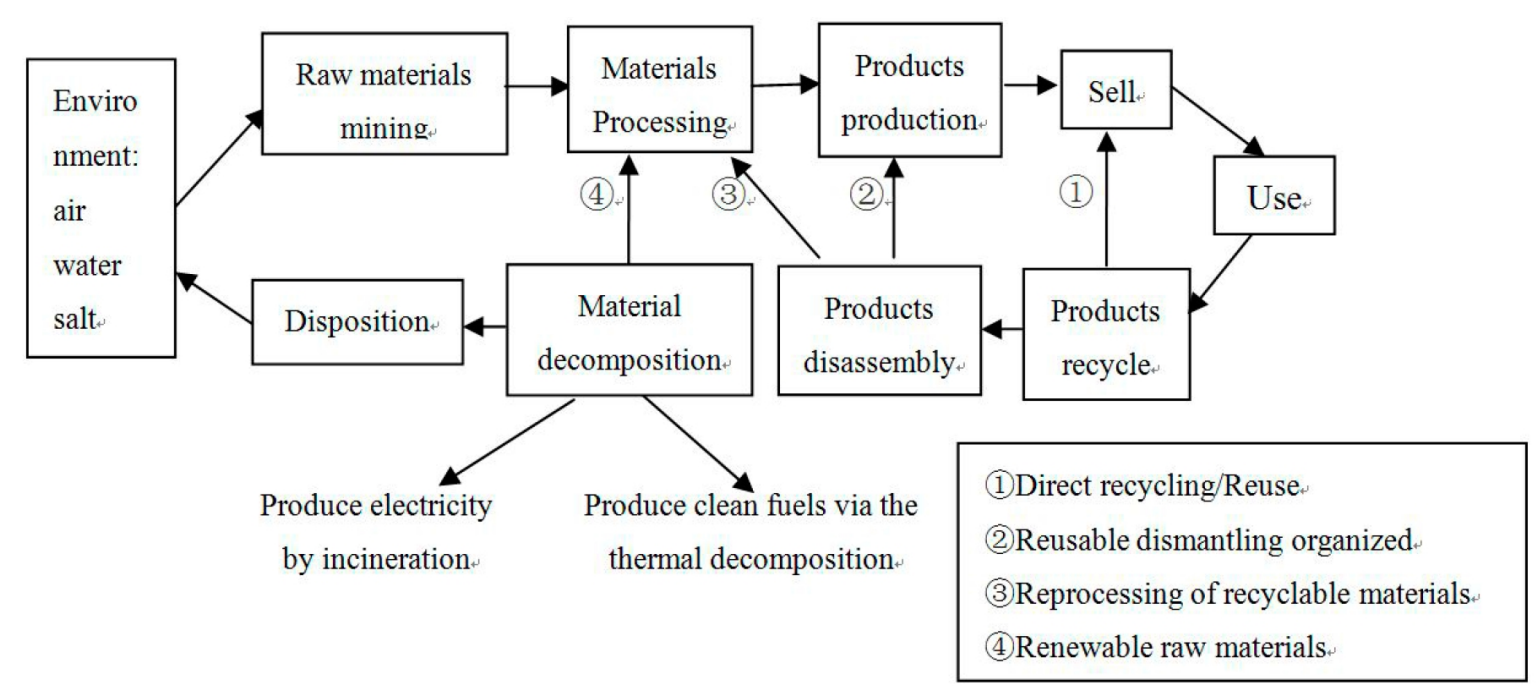

Figure 2. Resources flow route under an eco-design 
As shown in Figure 2, the resource flow route of eco-designed products differs from the single linear material flow route of traditional product design. The former can form an interactive flow route for resource recycling, which covers manufacture, sales, product use, recycle and waste disposal stages. At the same time, with the constant change of resource flow route, the resource value will form a cyclical resource value flow defined by a positive interaction between eco-design and resource value flow, promoting the continuous optimization of resource value flow. The logical association between ecological design and resource value flow is shown in Figure 3.

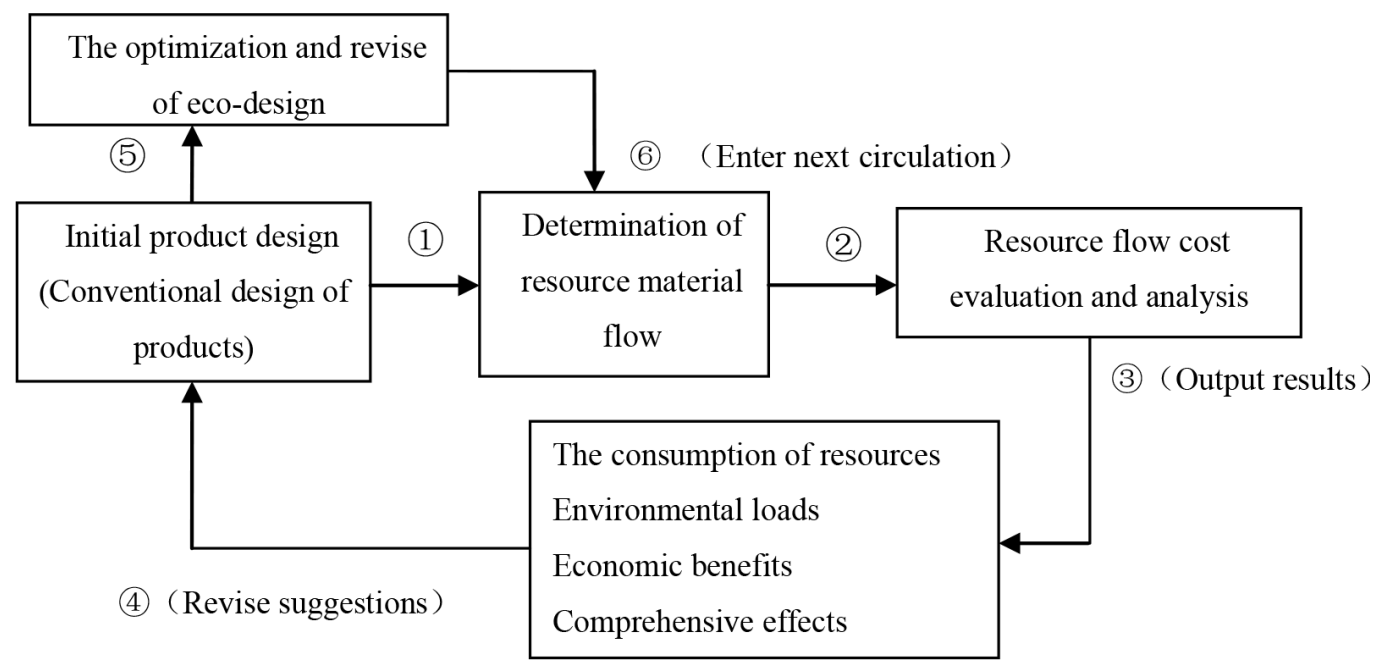

Figure 3. The logical correlation between the ecological design and resource flow cost

As depicted in Figure 3, the logical start of the interaction between ecological design and resource value stream is the initial product design, which determines initial material flow routes of the products in processes like $R \& D$, manufacturing, sales, utilization, maintenance and recycling disposal. According to the material flow route and product life cycle assessment model, it can be revealed that the resource consumption, the loss of the transfer cost of resources and environmental impact condition during the product lifecycle process, these analysis help enterprises to optimize or revise initial ecological design decisions and to enter the next round of eco-design (stage (5)). New eco-design will lead to changes in new material flow routes, and meanwhile its value flow. Analysis and evaluation on optimized resource value flow can reveal its improvements of resource efficiency, economic and environmental effects, and find out eco-design potential in production processes and technological process. Thus optimized control measures of resource value can be introduced into next round of eco-design.

Obviously, the feedback and optimization of information flow along with resource value circulated in plants ensures the output can respond quickly to the input. The eco-design in accordance with feedbacks of the value flow information, adjusts program to reducing costs, improving resource efficiency even further. Associated with the inherent logic in ecological 
design and resource value stream, ecological design can be improved continuously, and give impetus to optimizing the product resource material flow and value stream. Which becomes a spiraling a virtuous cycle, as well as improvements of products' usage, market and environmental value.

\section{Construction of Factors Analysis Model of Resource Value Stream in Product Life Cycle Based on Eco-Design}

\subsection{Evaluation and Analysis Model of Total Factor}

Figure 4 shows the interactive relationship among resource/energy consumption, economic value and environmental load. It is obvious that in the life cycle process of a product, the first step is to determine the production and use patterns through product design. Accompanied by resources and energy, the magnitude of the material and value for a product will be altered in various stages. Apart from some resources lost in the production and sales stages, most of the material is transformed into a new form of resources - completed goods, ready for consumption. As time passes, some parts go through a recycling system at the end of the product's life cycle, and other parts are abandoned. There will always exist the consumption of resources and energy and emissions of waste during the entire process of production, sales, use and recycling, all of which affect the environment.

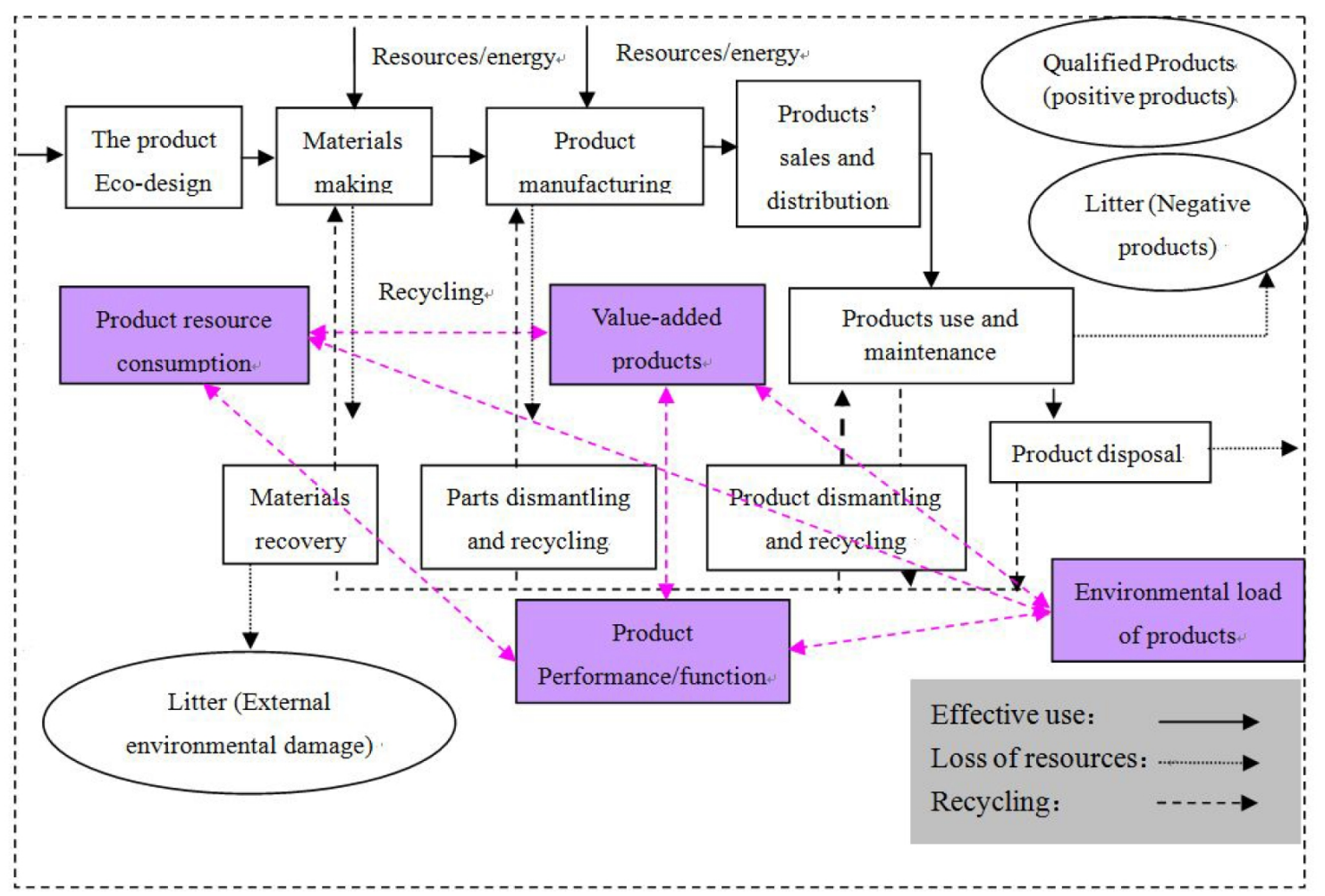

Figure 4. Cost accounting and analysis framework of resources flow based on eco-design 
To deconstruct the logical relationship among resource/energy consumption, economic value and environmental load, it is necessary to give a reasonable evaluation and analysis on the resource value stream in a product's life cycle process. Follow the idea of IPAT equation promoted by Chertow $(2001,2008)$ that environmental impact (I) can be presented as the continued product of population $(P)$, affluence $(A)$ and technology $(T)$. It can be illustrated by Figure 5 that the resource value analysis of the whole life cycle of products based on the ecodesign flow evaluation not only can be assessed in either product resources, economic, or environmental aspects of evaluation, but also by a factor combines comprehensive linkages of three dimensions. Equations (3) and (4).

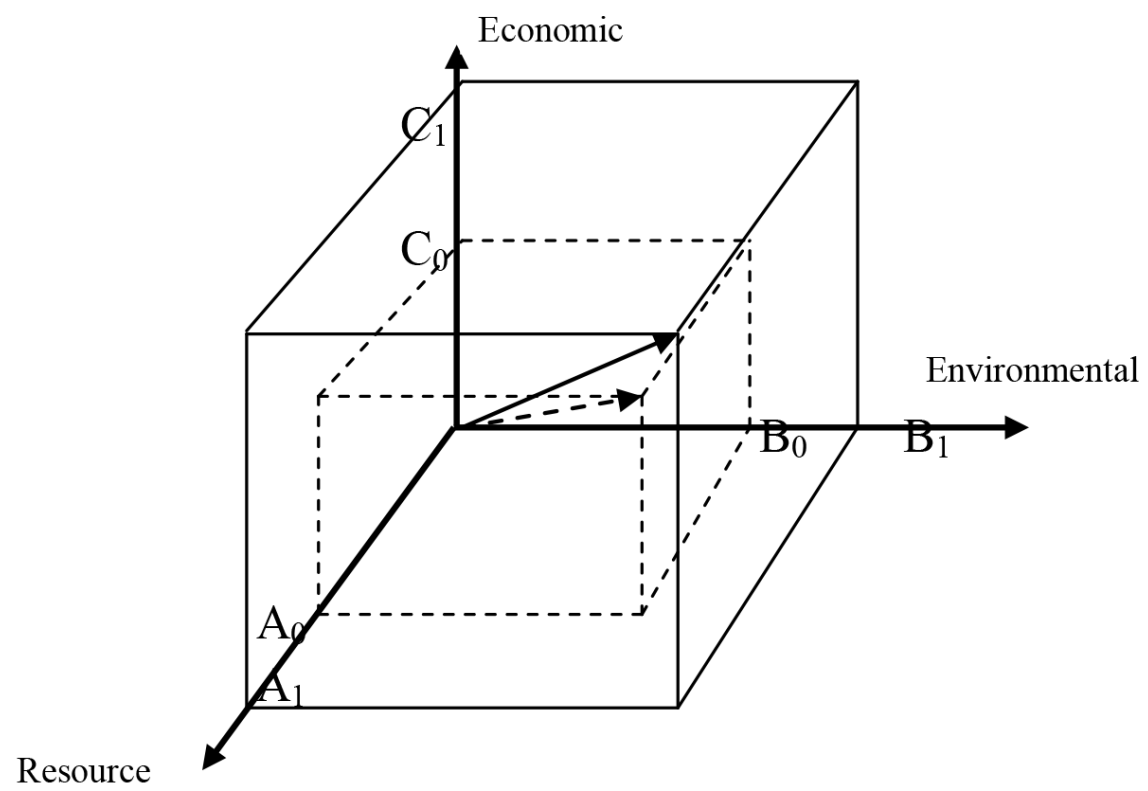

Figure 5. The total factor evaluation principle of resource value flow of product life cycle

$$
\begin{aligned}
& \frac{P E_{i}}{P R_{i}}=\frac{P V_{i}}{P R_{i}} \times \frac{P A V_{i}}{P V_{i}} \times \frac{P E_{i}}{P A V_{i}} \\
& P R E L_{i}=P R I_{i} \times P E I_{i} \times P E E_{i}
\end{aligned}
$$

In Equation (3) $P E_{i}$ is the environmental load of a product, which generally is the overall waste emissions of the product's life cycle, the economic assessment value of the environmental impact of a product; $P R_{i}$ is the resource consumption of product $i ; P V_{i}$ is the value of product $i$; $P A V_{i}$ is the added value of products $i$, generally the economic value added or industrial added value in practical application, while in Equation (4) $P R E L_{i}$ is the environmental load ratio of resource consumption in unit product $i$; $P R I_{i}$ is the resource efficiency of product $i$; $P E I_{i}$ is the economic efficiency of product $i$; and $P E E_{i}$ is the environmental efficiency of product $i$. 
Resulting from the equations above, the environmental load ratio of unit product's resource consumption can be resolved into a continued product of its resource efficiency, economic efficiency and environmental efficiency. This model analyzes a mutual association and quantitative relationship of resource consumption (resource efficiency), environmental impact (environmental efficiency), and economic benefits (economic efficiency), in the product's life cycle process. This further refines the analysis object into solid waste, $\mathrm{CO}_{2}, \mathrm{SO}_{2}$ emissions and so forth, replaces equation factors appropriately and dissects the logical relationship between the three factors from different angles.

\subsection{Evaluation and Analysis Model for Environmental Efficiency}

Researchers generally define environmental efficiency as the ratio of the value of a product or service and its environmental load. If analyzing the relative environmental efficiency of a product or whole categories of products from the product life cycle perspective, environmental efficiency of products can be used as such: Environmental efficiency = environmental load of product / added value of product as given by Equation (5), where $P E E_{i}$ is the environmental efficiency of products $i ; P E_{i}$ is the environmental load of products $i ; P A V_{i}$ is the added value of products $i$, and economic value added or industrial added value is generally used to represent the meanings.

$$
P E E_{i}=\frac{P E_{i}}{P A V_{i}}
$$

The evaluation value of environmental efficiency varies from before a product's eco-design or eco-design optimization to after. In order to evaluate and analyze the differences between these points, this paper obtains the relative environmental efficiency of a product by comparing environmental efficiency in a reporting period containing, i.e. $X$ multiple evaluation factors of a product is as in Equation (2).

Assuming $P E E_{0}, P E_{0}, P A V_{0}$ are the environmental efficiency, environmental load, and added value of product in base period, respectively; assuming $P E E_{1}, P E_{1}, P A V_{1}$ are the environmental efficiency, environmental load, and added value of product in reporting period, shown in Equation (6), where $X$ means $X$ multiple evaluation factors of a product, which are the environmental efficiency ratio before and after product eco-design; $X_{p a v}$ is the value coefficient of the product; and $X_{p e}$ is the reduce coefficient of the environmental impact of the product.

$$
\begin{aligned}
X=P E E_{1} / P E E_{0} & =\frac{P E_{1}}{P A V_{1}} / \frac{P E_{0}}{P A V_{0}}=\frac{P E_{1} \times P A V_{0}}{P E_{0} \times P A V_{1}}=\frac{P E_{1}}{P E_{0}} \times \frac{P A V_{0}}{P A V_{1}}=\frac{P A V_{0}}{P A V_{1}} \times \frac{P E_{1}}{P E_{0}} \\
& =1 /\left(\frac{P A V_{1}}{P A V_{0}}\right) \times 1 /\left(\frac{P E_{0}}{P E_{1}}\right)=1 /\left(X_{p a v}\right) \times\left(X_{p e}\right)
\end{aligned}
$$


Factor evaluation can be referred to the year by year comparison change of environmental efficiency, based on the actual production model through a quantitative evaluation of the data of the environmental value of the product in the full life cycle, thus become a very competitive green management evaluation tool of enterprises, which purpose is to help customers improving sustainable product and social responsibility awareness, in addition, evaluation factors can also prove the concept of environmental efficiency with respect to the potential advantage of the competitive market analysis by product eco-design and life cycle assessment. Factor evaluation can be used to evaluate and analyze the product before or after eco-design (or optimization) value of the product as well as the improvement of product environmental impact by the above formula. However, it is still unable to reflect the logical relationship among product function, the value of the product and the product environment load, which is eco-design need to focus on three core factors to consider. Therefore, by absorbing the value engineering principles, improvements of the evaluation of Factor $X$ Factor can be realized. The relationship among product function, the value of the product and the product environment load is defined as the integrated value of the production environment. As shown in Figure 6.

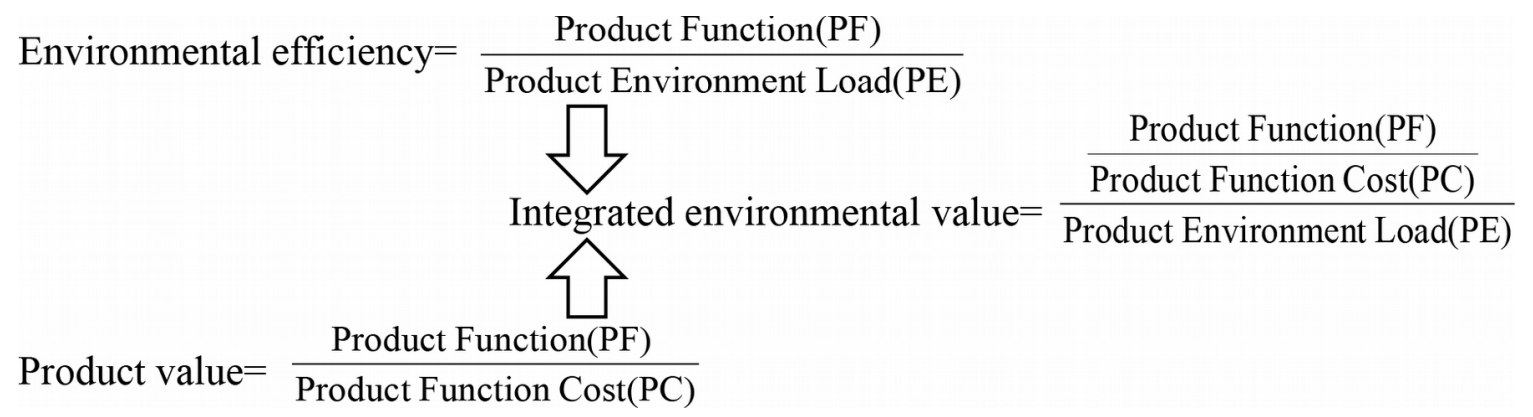

Figure 6. The concept of products environmental integrated value

To enhance the environmental values, we must enhance product performance, and reduce costs and environmental impact performance to achieve eco-design goals. By considering a product's integrated environmental value as a combination of the accounting method for $X$ multiple evaluation factors, Equation (7) is obtained, where $P E E_{i}^{\prime}$ is the improved environmental efficiency of product $i ; P V_{i}$ is the value of product $i ; P F_{i}$ is the product performance of product $i ; P E_{i}$ is the environmental load of product $i$; and $P C_{i}$ is the resources flow and environmental damage cost caused by functions of product $i$.

$$
P E E_{i}^{\prime}=P V_{i} / P E_{i}=P F_{i} /\left(P C_{i} \times P E_{i}\right)
$$

Informed by annual variations of a product's environmental efficiency, an improved $X$ multiple evaluation factors can be formed, where it is possible to assess any changes in the comprehensive value of products, as expressed by Equation (8), where $X^{\prime}$ is the improved $X$ multiples evaluation factor; $X_{p f}$ is the functioning coefficient of a product; $X_{p c}$ is the reduction 
coefficient of the function cost of a product; and $X_{p e}$ is the reduction coefficient of the environmental impact of a product.

$$
X^{\prime}=\frac{P E E_{1}^{\prime}}{P E E_{i}^{\prime}}=\frac{P F_{1} /\left(P C_{1} \times P E_{1}\right)}{P F_{0} /\left(P C_{0} \times P E_{0}\right)}=\frac{P F_{1}}{P F_{0}} \times \frac{P C_{0}}{P C_{1}} \times \frac{P E_{0}}{P E_{1}}=X_{p f} \times X_{p c} \times X_{p e}
$$

Equation (6) can be further calculated to correspond to the $\mathrm{CO}_{2}$ emissions factor of a product throughout its life cycle, and must be refined and evaluated.

\subsection{Evaluation and Analysis Model for Economic Efficiency}

In this paper, economic efficiency is defined as the additional output ratio of the unit value of a product's life cycle process. Economic efficiency of a product is the relative economic efficiency of a product or class of products for the product's system or product life cycle analysis, namely, economic efficiency of product $=$ the added value created by product/ product value as given by Equation (9), where $P E I_{i}$ is the economic efficiency of product $i$; $P V_{i}$ is the value of product $i$, which is the output value created by product $i$ generally; and $P A V_{i}$ is the added value of product $i$, generally defined as the economic value added, or industrial added value.

$$
P E I_{i}=\frac{P A V_{i}}{P V_{i}}
$$

The evaluation value of a product's economic efficiency varies from before the product eco-design or eco-design optimization to after. In order to facilitate evaluation and analysis of the differences before and after product eco-design, this paper compares the economic efficiency in the base period with that of the reporting period, and obtains the relative economic efficiency of a product, shown here as $Y$ multiple evaluation factors (Equation $2 a$ ).

$$
\text { Product } Y \text { multiple evaluation factors }=\frac{\text { economic-efficiency of new product }}{\text { economic-efficiency of old product }}
$$

Assuming $P E I_{0}, P V_{0}, P A V_{0}$ for economic efficiency, product value and the added value of product in the base period, respectively, and $P E I_{1}, P V_{1}, P A V_{1}$ for economic efficiency, product value and the added value of product in the reporting period can be according to Equation (10), where $Y$ is $Y$ multiples evaluation factors, namely the economic efficiency ratio before and after the product eco-design; $Y_{p v}$ is the value coefficient of the product; and $Y_{p a v}$ is the coefficient of the added value of the product.

$$
Y=P E I_{1} / P E I_{0}=\frac{P A V_{1}}{P V_{1}} / \frac{P A V_{0}}{P V_{0}}=\frac{P A V_{1} \times P V_{0}}{P A V_{0} \times P V_{1}}=\frac{P A V_{1}}{P A V_{0}} \times \frac{P V_{0}}{P V_{1}}=\frac{P A V_{1}}{P A V_{0}} \times 1 /\left(\frac{P V_{1}}{P V_{0}}\right)=Y_{p a v} \times 1\left(Y_{p V}\right)
$$




\subsection{Evaluation and Analysis Model for Resource Efficiency}

Resource efficiency is generally measured alongside resource productivity, that is, the analysis and evaluation of the efficiency of natural resources consumed by production activities. Resource productivity = economic and social development (magnitude of value) / consumption of natural resources (physical quantity), as given by Equation (11), where $R P I_{i}$ means the resource productivity of region or nation $i ; S V_{i}$ is the economic and social development of region or nation $i$, generally indicated by GDP; and $R R_{i}$ is the consumption of natural resources by region or nation $i$.

$$
R P I_{i}=\frac{S V_{i}(G D F)}{R R_{i}}
$$

According to a product system or product's life cycle, we can use resource productivity to analyze the relative efficiency of a product, class of products, or resources. Resource productivity (resource efficiency) of product $=$ the value created by product / resource consumption of product, as in Equation (12), where $P R I_{i}$ is the resource productivity of product $i ; P V_{i}$ is the output value creation of product $i$, generally defined as the industrial output value or product value; and $P R_{i}$ is the resource consumption of product $i$.

$$
P R I_{i}=\frac{P V_{i}}{P R_{i}}
$$

The evaluation value of product resource efficiency is different from before product eco-design to after. To evaluate the differences before to after product eco-design, this paper compares the resource efficiency of products in a base period with that of a reporting period, as far as gains in relative resource efficiency. This is the $Z$ multiples evaluation factor (Equation $2 b$ ).

$$
\text { Product } Z \text { multiple evaluation factors }=\frac{\text { resource-efficiency of new product }}{\text { resource-efficiency of old product }}
$$

Assuming $P R I_{0}, P V_{0}, P R_{0}$ is resource productivity, output value creation and resource consumption of product in base period, respectively; and assuming $P R I_{1}, P V_{1}, P R_{1}$ is resource productivity, output value creation and resource consumption of product in reporting period, as given by Equation (13), where $Z$ means $Z$ multiples evaluation factors of a product, namely the resource efficiency ratio before and after product eco-design; $Z_{p v}$ is the value coefficient of the product; and $Z_{p r}$ is the resource consumption reduction coefficient of the product.

$$
Z=P R I_{1} / P R I_{0}=\frac{P V_{1}}{P R_{1}} / \frac{P V_{0}}{P R_{0}}=\frac{P V_{1} \times P R_{0}}{P V_{0} \times P R_{1}}=\frac{P V_{1}}{P V_{0}} \times \frac{P R_{0}}{P R_{1}}=Z_{p v} \times Z_{p r}
$$




\section{Empirical Study}

Founded in 2003, the core business of T Co., Ltd., a Chinese SUV manufacturer, includes manufacturing automobile and engines, automobile molds, sheet metal parts, automobile transmissions and other key automobile parts.

This paper chose an SUV model that experienced eco-design during the year of 2014 and used the data before/after the eco-design in 2013/2015 to verify the availability of the evaluation and analysis model presented above. Product specifications and information are as following.

\begin{tabular}{|c|c|c|c|}
\hline & \multicolumn{3}{|c|}{ Specifications \& Information } \\
\hline & Before eco-design & $\begin{array}{l}\text { Improvement } \\
\text { direction }\end{array}$ & After eco-design \\
\hline Year & 2013 & & 2015 \\
\hline Length $\times$ Width $\times$ Height $(\mathrm{mm} \times \mathrm{mm} \times \mathrm{mm})$ & $4631 \times 1893 \times 1694$ & - & $4631 \times 1893 \times 1694$ \\
\hline Automobile transmission & MT & $\downarrow$ & MT \\
\hline Engine & 1.5T horsepower 160 & $\uparrow$ & 1.5T horsepower 164 \\
\hline Aspirated type & Turbo & - & Turbo \\
\hline Power steering & HPS & - & HPS \\
\hline Wheelbase (mm) & 2807 & - & 2807 \\
\hline Maximum speed $(\mathrm{km} / \mathrm{h})$ & 180 & - & 180 \\
\hline Accelerate time from 0 to $100 \mathrm{~km} / \mathrm{h}$ time $(\mathrm{s})$ & 9.9 & $\downarrow$ & 9.46 \\
\hline Average fuel consumption per $\mathrm{km}$ (L/100km) & 8.6 & $\downarrow$ & 7.8 \\
\hline Product life ${ }^{*}$ & 600000 & - & 600000 \\
\hline
\end{tabular}

*According to the Mandatory retirement standards for motor vehicles published by Chinese Commerce Department in 2013, the mandatory retirement standard of private vehicles is maximum mileage $600,000 \mathrm{~km}$. Available at: http://www.mofcom.gov.cn/article/b/d/201301/20130100003957.shtml

Table 1. Product specifications and information in 2013 and 2015

\subsection{Basic Calculation of $X$ and $Y$ Factor Model}

To simplify the basic calculation, suppose the product function values before/after eco-design are the same and equal to 1 .

In this paper, the greenhouse gas emissions of the model during its product life cycle has been calculated and converted into equivalent $\mathrm{CO}_{2}$ emissions by SimaPro 7.0 software. Using $600,000 \mathrm{~km}$ as a period, the $\mathrm{CO}_{2}$ emission of the type 2013 can be calculate as $11.3844 \times 10^{7} \mathrm{~kg}$, and $1.00398 \times 10^{7} \mathrm{~kg}$ for type 2015 .Resource consumptions of each type during product life cycle can be listed in the following table: 


\begin{tabular}{|c|c|c|c|c|c|}
\hline \multicolumn{3}{|c|}{ Type 2013 } & & Type 2015 \\
\hline $\begin{array}{c}\text { Resource } \\
\text { input }\end{array}$ & $\begin{array}{c}\text { Re-useable } \\
\text { resource }\end{array}$ & $\begin{array}{c}\text { Possibly } \\
\text { re-useable resource }\end{array}$ & $\begin{array}{c}\text { Resource } \\
\text { input }\end{array}$ & $\begin{array}{c}\text { Re-useable } \\
\text { resource }\end{array}$ & $\begin{array}{c}\text { Possibly } \\
\text { re-useable resource }\end{array}$ \\
\hline 30036.340 & 5743.600 & 26378.510 & 29073.330 & 6798.490 & 25755.950 \\
\hline
\end{tabular}

Table 2. Resource consumptions of each type (CNY)

Related calculations of type 2013 are as following:

$$
\text { Environmental efficiency }=\frac{\text { Product life } x \text { Product function }}{\text { Product environment load }}=0.0053
$$

Resource consumption during product life cicle

$=$ Resource input + Discarded resources

$=$ Resource input $\times 2-R e-$ useable resource-Possibly re-useable resource

$=$ CNY 27950.570

$$
\begin{aligned}
\text { Resource efficiency } & =\frac{\text { Product life } x \text { Product function }}{\text { Total resource consumption }} \\
& =\frac{\text { Product life } x \text { Product function }}{\text { Total resource value during full product life cycle }}=21.47
\end{aligned}
$$

Calculations of type 2015 are as following:

$$
\begin{aligned}
& \text { Environmental efficiency }=\frac{\text { Product life } x \text { Product function }}{\text { Product environment load }}=0.0060 \\
& \text { Resource consumption during product life cycle }=\text { CNY } 25592.220 \\
& \text { Resource efficiency }=23.440
\end{aligned}
$$

Thus the $\mathrm{CO}_{2}$ emission $\mathrm{X}$ factor of the model is 1.132 and $\mathrm{Z}$ factor is 1.092 .

\subsection{Improved Calculation and Analysis of $X$ and $Y$ Factor Model}

As traditional factor evaluation circulation models fail to consider the relationship between product function and its costs, in this paper, an improved model are discussed based on the results of the aforementioned evaluation factors.

To evaluate the function value of the product, Quality Function Deployment method (The quality function development is a method of developing new products which was put forward by Professor Yoji Akao, a Japanese scholar, in 1960s) has been applied. According to the 
principle of QFD method, the customer needs and product function relationship matrix sequentially utilize 9 points, 3 points or 1 point to assess the relationship between each other. After adding up all results, the weighted ratios of the respectively product function can be determined, which denotes function characteristics and key customer needs.

Standardize the changes during eco-design and times the weighted ratios of the respectively product function, the product function value ratio between each type can be seen as Table 3 .

\begin{tabular}{|c|c|c|c|c|}
\hline \multirow{2}{*}{ Product function characteristics } & \multicolumn{2}{|c|}{ Standardization table } & \multicolumn{2}{|c|}{$\begin{array}{l}\text { The weighted ratios of key } \\
\text { customer needs }\end{array}$} \\
\hline & Type 2013 & Type 2015 & Type 2013 & Type 2015 \\
\hline Length $\times$ width $\times$ height $(\mathrm{mm} \times \mathrm{mm} \times \mathrm{mm})$ & 1.000 & 1.000 & 0.010 & 0.010 \\
\hline Automobile transmission & 1.000 & 1.000 & 0.200 & 0.200 \\
\hline Engine & 0.976 & 1.000 & 0.215 & 0.220 \\
\hline Aspirated type & 1.000 & 1.000 & 0.190 & 0.190 \\
\hline Power steering & 1.000 & 1.000 & 0.140 & 0.140 \\
\hline Wheelbase (mm) & 1.000 & 1.000 & 0.010 & 0.010 \\
\hline Maximum speed $(\mathrm{km} / \mathrm{h})$ & 1.000 & 1.000 & 0.020 & 0.020 \\
\hline Accelerate time from 0 to $100 \mathrm{~km} / \mathrm{h}$ time (s) & 0.956 & 1.000 & 0.019 & 0.020 \\
\hline Average fuel consumption per $\mathrm{km}(\mathrm{l} / 100 \mathrm{~km})$ & 0.907 & 1.000 & 0.136 & 0.150 \\
\hline Product life* & 1.000 & 1.000 & 0.040 & 0.040 \\
\hline Total & & & 0.980 & 1.000 \\
\hline
\end{tabular}

*According to the Mandatory retirement standards for motor vehicles published by Chinese Commerce Department, the mandatory retirement standard of private vehicles is maximum mileage $600,000 \mathrm{~km}$.

Table 3. the product function value ratio between type 2013 and type 2015

Product function costs are provided by the company as following.

\begin{tabular}{|c|r|r|r|}
\hline Type & $\begin{array}{c}\text { Inner } \\
\text { component }\end{array}$ & $\begin{array}{c}\text { Outer } \\
\text { component }\end{array}$ & \multicolumn{1}{|c|}{ Total } \\
\hline 2013 & 28007.620 & 13926.700 & 41934.320 \\
\hline 2015 & 26631.880 & 11043.070 & 37674.950 \\
\hline
\end{tabular}

Table 4. Costing table for type 2013 and type 2015

$\mathrm{CO}_{2}$ emission and resource consumptions of each type are remain the same as above calculation. 


\begin{tabular}{|l|r|r|}
\cline { 2 - 3 } \multicolumn{1}{c|}{} & Type 2013 & \multicolumn{1}{c|}{ Type 2015 } \\
\hline Product function value & 0.980 & 1.000 \\
\hline Product environment load & 113844000 & 100398000 \\
\hline Product resource consumption & 27950.570 & 25592.220 \\
\hline Product function cost & 41934.320 & 37674.950 \\
\hline
\end{tabular}

Table 5. $\mathrm{X}$ factor and $\mathrm{Z}$ factor calculation preparation

Thus the improved $\mathrm{CO}_{2}$ emission $\mathrm{X}$ factor of the model is 1.288 and $\mathrm{Z}$ factor is 1.241 . Been compared to the result of basic analysis, the improved environmental efficiency and resource efficiency $(1.132 \rightarrow 1.288,1.092 \rightarrow 1.241)$ shows that the improved factor evaluation model can assess the environment, resource and economic efficiency factor value during the product life cycle as well as evaluate the logical relationship among each other more comprehensively, effectively and rationally.

\section{Conclusions}

By dissecting the internal logical relationship between a product's eco-design and the evaluation of its resource value flow, and integrating the analysis theory of resource value flow evaluation into the entire life cycle process of the product, this paper builds an integrated factor analysis model for product life cycle management based on eco-design which combines product resource efficiency, economic efficiency and environmental efficiency. The model can not only promote the importance of resource value circulation in the overall life cycle process and analyze the mutual logical relationship of product function, value, resource consumption and environmental load, but also comprehensively evaluate and analyze material and value flow at every stage of the product life cycle process, revealing the symptoms and the potential location of different aspects, thus providing comprehensive, accurate and timely decision-making information about production and management activities enterprise managers. The empirical study shows the integrated factor analysis model can improve the evaluation by considering the logic relationship among product function, product function cost and product environment load during its life cycle.

However, product eco-design requires a balance between three dimensions: resource consumption, environmental protection and economic performance, which are interdependent. Therefore, analysis of the internal logical relationship of these three dimensions still precludes comprehensive evaluation of development status. How do we bridge the gap between the resource environment and economic management field? These issues require further research. 


\section{Acknowledgments}

I would like to thank Prof. Ling Zheng, Prof. Xu Xiao and all the seminar participants at Central South University for their valuable comments and discussions. I also appreciate the two anonymous responders who provided much sound advice on this paper. I'd like to extend my thanks to my wife for her work grammar-checking and editing this paper. All remaining errors are my own.

This research work was supported by the National Natural Science Funds of China (No.71303263), the Humanities and Social Sciences Program Fund of Ministry of Education (No.11YJC790312), the Doctoral Fund of Ministry of Education (No.20130162120045), the Major Program of the National Social Science Fund of China (No.11\&ZD166), the Key Project of Philosophy and Social Sciences Research of Ministry of Education (No.13JZD0016), The Energy-saving and Emission Reduction Demonstration Project of Changsha City (No. CSCG-HNSZ-DY20131002, Procurement of [2013D]0012 -1 Changsha Finance), The Social Sciences Program Fund of Hunan Province (13YBA353), The Soft Science Program of Hunan Province(2014ZK3124).

\section{References}

Aoe, T. (2006). Eco-Efficiency (Factor X) for Electrical and Electronic Products and a Case Study on Home Appliances in a Household. Materials Transactions, 47, 913-922. http://dx.doi.org/10.2320/matertrans.47.913

Aoe, T. (2007). Eco-efficiency and ecodesign in electrical and electronic products. Journal of Cleaner Production, 15, 1406-1414. http://dx.doi.org/10.1016/j.jclepro.2006.06.004

Bhander, G., Hauschild, M., \& McAloone, T. (2003). Implementing life cycle assessment in product development. Environmental Progress and Sustainable Energy, 22, 255-267. http://dx.doi.org/10.1002/ep.670220414

Chertow, M.R. (2001).The IPAt equation and its variants; changing views of technology and environmental impact. Journal of Industrial Ecology, 4, 13-29.

http://dx.doi.org/10.1162/10881980052541927

Chertow, M. (2008). IPAT equation. Available at: http://www.eoearth.org/view/article/153641 
COM (2003). Communication from the Commission to the Council and the European Parliament-Integrated Product Policy-Building on Environmental Life-Cycle Thinking /*COM/2003/0302 final*/. Available at: http://eur-lex.europa.eu/legal-content/EN/TXT/HTML/? uri $=$ CELEX:52003DC0302\&from $=$ EN

Graedel, T.E., Allenby, B.R., \& Comrie, P.R. (1995). Matrix approaches to abridged life cycle assessment. Environmental Science \& Technology, 29, 134-142.

Jeganova, J. (2004). Product Life Cycle design: integrating environmental aspects into product design and development process at Alfa Laval. MSc Thesis. Lund University Sweden.

Jonsson, A., \& Svensson, T., (1997). Life cycle assessment of flooring materials: case study. Building and Environment, 32, 245-255. http://dx.doi.org/10.1016/S0360-1323(96)00052-2

Muñoz, I., Rodríguez, A., Rosal, R., \& Fernández-Alba, A.R., (2009). Life Cycle Assessment of urban wastewater reuse with ozonation as tertiary treatment: A focus on toxicity-related impacts. Science of Total Environment, 407, 1245-1256.

http://dx.doi.org/10.1016/j.scitotenv.2008.09.029

Ortiz, M., Raluy, R.G., \& Serra, L. (2007). Life cycle assessment of water treatment technologies: Waste water and water- reuse in small town. Desalination, 204, 121-131. http://dx.doi.org/10.1016/j.desal.2006.04.026

Renou, S., Thomas, J.S., Aoustin, E., \& Pons, M.N. (2008). Influence of impact assessment methods in waste water treatment LCA. Journal of Cleaner Production, 16, 1098-1105. http://dx.doi.org/10.1016/j.jclepro.2007.06.003

Sakao, T. (2007). A QFD-centred design methodology for environmentally conscious product design. International Journal of Production Research, 45, 4143-4162. http://dx.doi.org/10.1080/00207540701450179

Spengler, T., Geldermann, J., Hahre, S.H., Sieverdingbeck, A., \& Rentz, O., (1998). Development of a multiple criteria based decision support system for environmental assessment of recycling measures in the iron and steel making industry. Journal of Cleaner Production, 6, 37-52. http://dx.doi.org/10.1016/S0959-6526(97)00048-6

Takahashi, T.(2005). Evaluation methods and Applications of Factor X Indicator for Realization of a Sustainable Society. Fourth International Symp. on EcoDesign 2005: Environmentally Conscious Design and Inverse Manufacturing. Tokyo, 770-774. http://dx.doi.org/10.1109/ecodim.2005.1619347

van der Velden, N.M., Kuusk, K., \& Köhler, A.R., (2015). Life cycle assessment and eco-design of smart textiles: The importance of material selection demonstrated through e-textile product redesign. Materials \& Design, 5, 313-324. http://dx.doi.org/10.1016/j.matdes.2015.06.129 
Xiong, F., Xiao, X., Chen, X., \& Zhou, Z. (2015). The Path Optimization of Chinese Aluminum Corporation for Circular Economy Strategy Based on Resource Value Flow Model: A Case Study of CHINALCO. Environmental Engineering and Management Journal, 14(8), 1923-1932.

Yamamoto, R. (1999). Eco-Design Best Practice 100. Diamond, Inc. 55 (in Japanese).

Yamamoto, R., \& Wang, T., (2003). The strategic environmental management for ecological design - example 100. Chemical Industry Press, 165-169 (in Chinese).

Zhou, Z. (2014). On Evaluation Model of Green Technology Innovation Capability of Pulp and Paper Enterprise Based on Support Vector Machines. Advanced Materials Research, 886 285-288. http://dx.doi.org/10.4028/www.scientific.net/amr.886.285

Zhou, Z., Chen, X., \& Xiao, X. (2013a). On evaluation model of circular economy for iron and steel enterprise based on support vector machines with heuristic algorithm for tuning hyperparameters. Applied Mathematics \& Information Sciences, 7, 2215-2223. http://dx.doi.org/10.12785/amis/070611

Zhou, Z., Chen, X., Xiao, X., \& Xiong, F. (2013b). A comprehensive evaluation indicators system of sustainable consumption and production in the iron and steel industry: a field study in baosteel. Metalurgia International, 18, 119-129.

Article's contents are provided on an Attribution-Non Commercial 3.0 Creative commons license. Readers are allowed to copy, distribute and communicate article's contents, provided the author's and Journal of Industrial Engineering and Management's names are included. It must not be used for commercial purposes. To see the complete license contents, please visit http://creativecommons.org/licenses/by-nc/3.0/. 